\title{
C. Vinti, La monnaie de l'absolu. Jean-Luc Godard. Du musée de l'imaginaire au musée du réel
}

\section{Francesca Piselli}

\section{(2) OpenEdition}

\section{Journals}

Édition électronique

URL : http://journals.openedition.org/studifrancesi/10606

DOI : 10.4000/studifrancesi. 10606

ISSN : 2427-5856

Éditeur

Rosenberg \& Sellier

\section{Édition imprimée}

Date de publication : 1 décembre 2017

Pagination : 588-589

ISSN : 0039-2944

\section{Référence électronique}

Francesca Piselli, « C. Vinti, La monnaie de l'absolu. Jean-Luc Godard. Du musée de l'imaginaire au musée du réel », Studi Francesi [En ligne], 183 (LXI | III) | 2017, mis en ligne le 01 février 2018, consulté le 21 janvier 2021. URL : http://journals.openedition.org/studifrancesi/10606 ; DOI : https://doi.org/ 10.4000/studifrancesi.10606

Ce document a été généré automatiquement le 21 janvier 2021.

\section{(c) $($ ) $\odot$ (8)}

Studi Francesi è distribuita con Licenza Creative Commons Attribuzione - Non commerciale - Non opere derivate 4.0 Internazionale. 


\title{
C. Vinti, La monnaie de l'absolu. Jean- Luc Godard. Du musée de l'imaginaire au musée du réel
}

\author{
Francesca Piselli
}

\section{RÉFÉRENCE}

Claudio VINTI, La monnaie de l'absolu. Jean-Luc Godard. Du musée de l'imaginaire au musée du réel, Lanciano, Carabba, 2017, «Testi e Ricerche. Studi di cultura francese e italiana», 148 pp.

1 Ce volume se compose de onze chapitres: neuf sont consacrés à Jean-Luc Godard et deux à André Malraux. Celui-ci, comme le rappelle Claudio Vinti dans sa «Présentation», a exercé une influence profonde sur le réalisateur franco-suisse. Par l'emprunt du titre La monnaie de l'absolu (1998) pour le sixième épisode des Histoire(s) du cinéma, Godard rend hommage à Malraux pour sa réflexion sur l'art. C'est précisément au langage de l'art dans l'œuvre de Malraux que sont consacrés le premier et le dernier chapitres. À travers l'art, c'est un pouvoir extraordinaire qui va se révéler à l'homme: la possibilité de récréer le monde et de le recomposer selon sa liberté créatrice. Ainsi, quand un artiste devient partie intégrante de ce «musée Imaginaire» universel que Malraux a conçu, la présence dans son travail de cette liberté créatrice est pleinement reconnue par la postérité.

2 L'Art et l'idée de liberté de création ont incontestablement nourri la réflexion de Godard sur le cinéma. Le réalisateur, tel un démiurge, est le seul capable de faire dialoguer les œuvres (visuelles ou sonores, contemporaines ou anciennes) entre elles. De plus, la relation qu'il propose entre image et texte est alimentée par une bibliothèque imaginaire, à la façon du Musée imaginaire de Malraux. À l'instar de ce dernier, qui estime que l'artiste se doit de transformer la signification du monde et que le roman doit créer une réalité autre, Godard, par le montage, a démontré que le 
cinéma et le reportage sont le «musée du réel» et que les images n'ont de sens que pour transformer le monde. Cependant, à cette quête correspond un prix à payer: «la monnaie de l'absolu».

3 Les aspects centraux de l'œuvre godardienne, à savoir la communication, le souci pour les mots et le rôle du dialogue (chapitres III, VII et VIII) sont scrupuleusement pris en compte par Vinti. L'A. souligne que, depuis l'accent étranger de Jean Seberg dans À bout de souffle (1959) jusqu'au dernier film Adieu au langage (2014), les différentes situations qui nous sont présentées ne sont que les bribes d'un discours que le réalisateur francosuisse se tient à lui-même, un soliloque et une solitude qui sont un appel à la communication. Il n'en reste pas moins que la communication humaine semble mourir et que le recours au «non-dit» s'avère indispensable. En effet, à côté d'un «dit» de plus en plus fragmenté et cryptique, un «non-dit» multiforme et varié apparaît (chapitre X). Parfois, le «non-dit» est bien plus parlant que le «dit», notamment dans une société où le dialogue entre des personnages souvent égarés devient une formidable gageure.

4 Le rôle joué par le dialogue dans le cinéma godardien est discuté dans le chapitre VIII. La langue quotidienne envahit les échanges, qui sont souvent ponctués par des bruits du réel ou rythmés par la musique et une nouvelle écriture basée sur le montage s'impose alors en rupture avec la tradition cinématographique.

5 La politique et l'économie sont passées au crible dans les chapitres IV et V. Chez Godard il est impossible de séparer politique et cinéma: filmer est un acte politique, estime-t-il. Il aborde les points sensibles de la situation politique, sociale, aussi bien qu'économique de l'époque et ce sont les transformations déterminées par celle-ci qui l'interpellent. Depuis ses premiers films, en particulier À bout de souffle, en passant par Deux ou trois choses que je sais d'elle (1966) et Week-end (1967), jusqu'à Film socialisme (2010), il n'a pas manqué de porter un regard attentif sur le capitalisme et le monde de l'argent.

6 Nous ne saurions terminer sans évoquer deux autres points de vue offerts par le livre de Claudio Vinti. Le premier concerne le rôle de la mode dans le cinéma et l'importance de ce qu'on peut appeler le style Nouvelle Vague pour les jeunes des années 60 (chapitre VI). L'habillement devient un élément révolutionnaire marquant une différence par rapport au passé et témoigne en même temps de la volonté d'un changement identitaire. Le second évoque la relation de Jean-Luc Godard avec l'Italie (chapitre IX), toujours attiré par la culture et le cinéma italiens. Les rapports du réalisateur franco-suisse avec le Bel paese ont été souvent contrastés, surtout à cause de la censure, qui a été implacable à l'encontre d'à bout de souffle, La chinoise (1967) et Weekend. À ce sujet, il n'est pas inutile de rappeler que Godard n'a pas reconnu la paternité de la version italienne de Le mépris (1963), dénaturé, d'après lui, par les coupes et les ajouts imposés par le producteur Carlo Ponti.

7 Tous ceux qui s'intéressent à l'œuvre non seulement de Godard, mais aussi de Malraux, trouveront dans ce volume un outil incontournable pour approfondir l'étude de ces deux intellectuels majeurs des $\mathrm{Xx}^{\mathrm{e}}$ et $\mathrm{XXI}^{\mathrm{e}}$ siècles. 